\title{
CARACTERIZACIÓN FÍSIOGRÁFICA DE LA PUNA DE SAJAMA, CORDILLERA OCCIDENTAL DE LOS ANDES (BOLIVIA)
}

\author{
Puna Physiographic Characterization of Sajama \\ (West Of The Andes Mountains) \\ Fernando Javier Santa Cecilia Mateos ${ }^{1}$ y Rafael Mata Olmo ${ }^{2}$
}

Recibido: 03/03/2013 Aceptado: 05/06/2013

Resumen. Este artículo aproxima a la realidad física de la cordillera Occidental de los Andes. Un espacio geográfico donde los caracteres geológicos relacionados con el vulcanismo adquieren una relevancia especial en la configuración del paisaje andino. Los nevados y llanuras intermedias o altiplanos, son los dos elementos que constituyen la imagen de la puna andina, un territorio situado por encima de los 4.000 metros, ámbito intermedio entre los valles húmedos o yungas y las más altas cumbres de los Andes. A la singularidad volcánica habría que añadir la relacionada con el modelado glaciar, los aspectos hidrográficos y la biogeografia en esta área. El artículo toma como ejemplo de estudio la puna de Sajama en el departamento de Oruro, en la frontera boliviano-chilena.

Palabras clave: Los Andes, vulcanismo, puna andina, nevados, queñua, bofedal, cordillera Occidental.

Abstract. This article approaches the physical reality of the Western Cordillera of the Andes. A geographical space where characters related geological volcanism are of particular importance in shaping the landscape Andean. The intermediate plains or mountains and plateaus, are the two elements that make up the image of the Andean puna, an area located above 4,000 meters, the middle ground between Yungas wet valley and the highest peaks of the Andes. A volcanic uniqueness should add that related to glacier modeling, hydrographic aspects and biogeography in this area. The article uses the example of the highlands of Sajama study in the department of Oruro in Bolivian-Chilean border.

Key words: Los Andes, vulcanismo, puna andina, nevados, queñua, bofedal, cordillera Occidental.

\section{BASES FÍSICAS DE LA PUNA DE SAJAMA}

Este capitulo aporta una sintesis de los aspectos más relevantes del medio físico del extremo suroccidental de Bolivia, más concretamente de la cordillera Occidental de los Andes, en la frontera con Chile. En él se aportan breves reseñas sobre la orografía de la zona y de las bases litológicas, tectónicas y geomorfológicos que arman esta cordiIlera; se señalan los rasgos principales del clima local en el

contexto regional, seguido de las líneas básicas sobre la red hidrográfica e hidrológica, finalmente se realiza una breve caracterización biogeográfica de este espacio andino.

\subsection{Marco regional: los Andes}

Desde las estribaciones del Caribe hasta el sur de Patagonia, los más de $7.200 \mathrm{~km}$ de los Andes constituyen la

(1) Profesor de Geografia de la UNED. fsantacecilia@madrid.uned.es

(2) Catedrático de Análisis Geográfico Regional de la UAM. rafael.mata@uam.es 


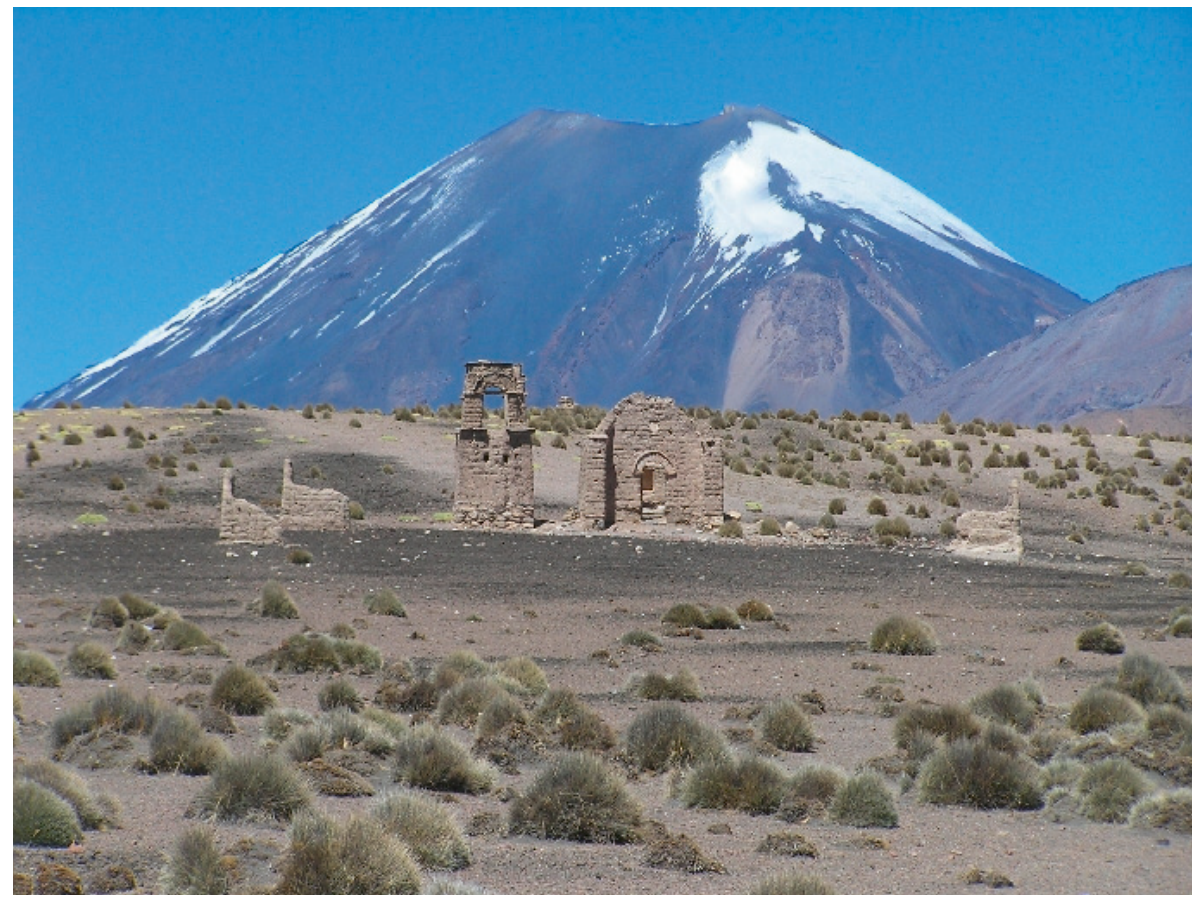

FIgURA 1. Estratovolcán Parinacota (6.348 m). Fotografía del autor.

cordillera más larga del mundo. El término Andes significa gradas o terrazas, en referencia al modo en que las diversas culturas andinas aprovecharon los recursos de sus laderas ${ }^{3}$.

La prosperidad del espacio andino gracias al aprovechamiento de determinadas zonas que permitían el tipo de cultivos en terrazas, siempre acorde con la naturaleza y sus dinámicas, permitió el desarrollo de civilizaciones como la de Tiahuanako y su heredera, la incaica. El avance de estas culturas milenarias de las cuales aún existen testimonios, estuvo basada en un minucioso conocimiento de los recursos, alcanzando el grado de domesticación de múltiples plantas y también el aprovechamiento de algunos animales como llamas y alpacas.

Se consideran señas de identidad física de este territorio los extensos lagos y saladares, muchos de los cuales vertebran las fastuosas cadenas que dan forma a esta cordillera. La visión de estos lugares como almacén de recursos convierte este medio en un espacio habitable, permitiendo el desarrollo de otras actividades como la pesca y la navegación, complementarias de la agricultura. El ejemplo más expresivo es el lago Titicaca, donde dicen que habita el dios inca Virakocha.

Los Andes no son únicamente una imponente forma de relieve; en torno a ellos converge un amplio legado de símbolos que no hacen más que enriquecer el carácter de esta cordillera. De las civilizaciones antes citadas y del desarrollo de éstas a lo largo de los tiempos, emanan unos valores etnográficos y culturales inagotables. El pacha-kuti o cambio histórico-temporal que supuso la llegada de los conquistadores, significó un cese de estas añosas culturas, estando aún presentes elementos fascinantes como los kallawalla u hombres medicina, viajeros intemporales de los Andes, o las diversas prácticas agrícolas que respetan y mejoran los suelos y que se alían con la utilización de una gran diversidad de plantas tropicales.

En sintesis, se trata de un territorio donde el factor social es fundamental, materializado en unos hechos humanos casi siempre en armonía con la naturaleza, gravitando en torno a la Pachamama siempre recordada con el vuelo del cóndor, la imagen de los camélidos, el titi, el suri, los flamencos o el temido puma, verdaderos símbolos de las culturas andinas.

\subsubsection{El medio andino}

Con una longitud de $7.200 \mathrm{~km}$ y una altura media de $4.000 \mathrm{~m}$ es comprensible que los ambientes que se dan en los Andes sean extremadamente diversos; por este motivo son muchos los autores que plantean una división latitudinal y una de hábitats principales. La clasificación latitudinal distingue tres divisiones para el conjunto de los Andes: Andes septentrionales, Andes centrales y Andes australes 0 patagónicos ${ }^{4}$. Por su parte, la división en sub-regiones 0 hábitats principales de los Andes distingue el Páramo, que se extiende de forma discontinua por las partes altas de los

(3) Algunos autores atribuyen también su origen a la palabra Quetchua Anti, que era el nombre que recibian los pobladores de algunas selvas altas de Perú.

(4) Siguiendo la clasificación de Gansser (1973). 
Andes septentrionales y por el norte de los Andes centrales. El segundo hábitat es la Puna, que se extiende hacia el sur, de rasgos climáticos más secos que el anterior dominio y que forma un continuo sobre la totalidad del altiplano.

La división anterior se establece a pequeña escala, podría denominarse regional, de acuerdo con los criterios latitudinales citados. Sin embargo, como no puede ser otra forma, a medida que se desciende a analizar el territorio se establecen diferencias que dan lugar a subregiones. Por ejemplo, la gran humedad de los Andes septentrionales y de los Andes centrales por el lado oriental favorece la existencia de bosques de ladera de tipología muy diversa, mayoritariamente de hoja perenne, formando la región de los Yungas o bosques montanos de los Andes.

A la hora de caracterizar las subregiones, hay que señalar algunos rasgos que resultan claves. Por un lado la vegetación, tanto en el páramo como en la puna: las plantas que dan vida a los diferentes ecosistemas están adaptadas a altas radiaciones, baja presión atmosférica y a fuertes vientos con efecto desecante. La dureza de estas condiciones queda reflejada en la vegetación que crece y se descompone con lentitud, por lo que ambos ambientes tardan mucho en recuperarse de las perturbaciones humanas (Sánchez, I. 2011).

Los cambios de temperatura diarios son casi mayores que los de las estaciones, bajando por la noche de cero grados, incluso cerca del ecuador. Los vientos alisios, que traen aire húmedo desde el Este, convierten a los Andes tropicales orientales en más húmedos, pues cuando el aire se ve obligado a ascender por las laderas condensa y descarga la humedad que contiene, lo que facilita que el bosque alcance cotas superiores.

En contraste, las más secas laderas occidentales de los Andes centrales facilitan la existencia de fuertes diferencias térmicas y heladas más frecuentes. Esto se debe a la falta del efecto amortiguador de la irradiación de la humedad atmosférica, que encuentra su mayor expresión en los desiertos andinos de la puna seca y en las laderas que dan al desierto de Atacama.

Más al sur, en los Andes australes o patagónicos, los vientos húmedos del Pacífico permiten la existencia de las selvas templadas valdivianas y bosques magallánicos en la vertiente occidental, pero cuando atraviesan la cordillera y llegan a la ladera oriental, su aire, ya seco, provoca la aparición de estepas semiáridas. En las cumbres se desarrollan campos de hielo, tundras y una escasa vegetación altoandina limitada por el frío. Los diversos valles transversales que casi sólo se dan en los Andes australes contribuyen a su función como corredores para la biota.

En lo referente al clima de los Andes, resulta difícil de definir en patrones generales debido a la importante extensión que ocupa esta cordillera y a su complejidad. Desde los $6.959 \mathrm{~m}$ del Aconcagua hasta el nivel del mar, los cinturo-

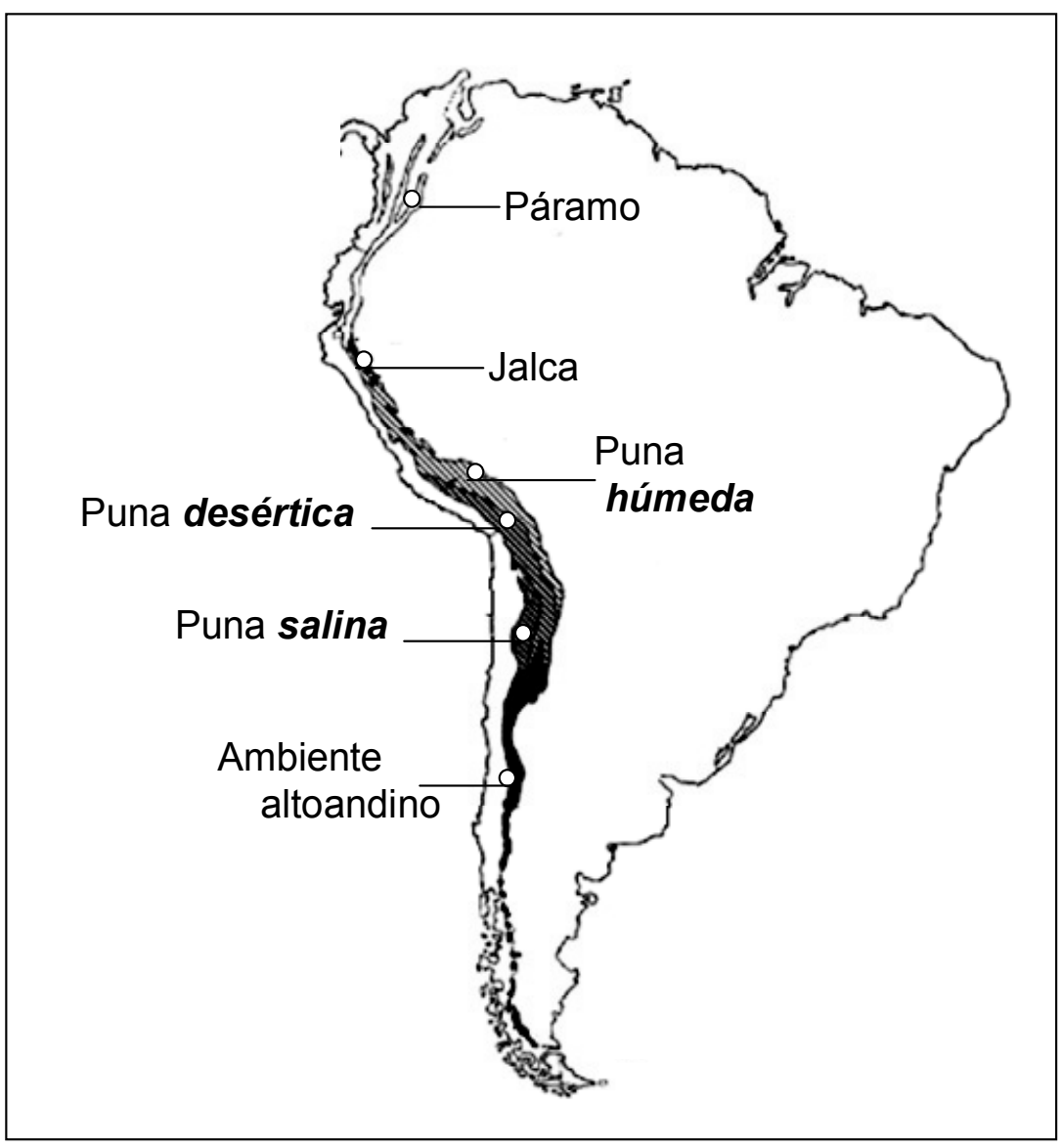

FIGURA 2. Principales hábitats de la cordillera de los Andes. Fuente: Elaboración propia basado en Gansser (1973). 
nes altitudinales varían notablemente con las condiciones locales como topografía, tipos de suelo, vientos, proximidad al mar, nubosidad, o la irradiación que varía notablemente con la posición de las laderas. Además, los cambios en poco espacio de los Andes pueden ser muy contrastados, como el paso de la puna andina a los yungas, mientras que otros son tan paulatinos que apenas se perciben las variaciones con la latitud, la elevación o la orientación de las cordilleras interandinas.

Aun así, Humboldt aportó una generalización climática de los pisos altitudinales que relacionó con la distribución de las plantas por alturas. En ella distinguía entre tierra caliente, de 0 a $1.000 \mathrm{~m}$, tierra templada, de 1.000 a $2.500 \mathrm{~m}$ y tierra fría, de 2.500 a $3.500 \mathrm{~m}$. Más recientemente, a estas se les ha añadido el piso denominado tierra helada, que incluye las alturas superiores a los 3.500 m. Esta clasificación coincide a grandes rasgos con ciertos divisiones naturales de la vegetación, que según las alturas antes señaladas, incluirian: los bosques Iluviosos de tierras bajas hasta los $1.000 \mathrm{~m}$, los bosques montanos bajos entre los 1.000 y 2.500 , los bosques nublados o ceja de montaña entre los 2.500 y 3.500, y a partir de los 3.500 m, el páramo en los Andes septentrionales y la puna en los centrales.

\subsection{La puna de Sajama}

Se trata de un área del altiplano Central de Bolivia que encuentra su límite occidental en la Cordillera Occidental de los Andes, frontera natural con Chile, constituida por extensas altiplanicies o punas, e importantes nevados de naturaleza volcánica como el Cerro Sajama, los Payachatas o el Anallajchi. Dentro de este espacio se encuentra el Parque Nacional Sajama, ámbito de protección al que nos referiremos con frecuencia (de ahora en adelante PNS).

La zona de estudio se caracteriza por albergar una alineación de antiguos edificios volcánicos de edad pliocena, cuya altura supera los 6.000 metros y en donde aún persisten pequeños aparatos glaciares en áreas de cumbres. La red hidrográfica se organiza en extensos valles, algunos en forma de artesa, que comunican las partes altas con las zonas más deprimidas topográficamente, y en las que se asientan las aldeas y estancias localizadas cerca de los ríos Sajama, Isquillani y Tomarapi. La fisonomía de estas tierras se caracteriza por la presencia de grandes pampas o praderas que enlazan, a través de extensos glacis, con las serranías y cerros aislados -sayas- que jalonan los grandes nevados de esta cordillera volcánica.

En sintesis, se trata de un territorio homogéneo, con presencia de amplios valles intramontañosos y una cordillera definida por una topografía accidentada en zonas altas y en donde los grandes relieves de cumbres quedan constituidos por materiales de origen volcánico, muy vulnerables a la erosión, acrecentada por la escasa cobertura vegetal y las particulares condiciones climáticas de una zona tan árida. Este sector de la puna es una de los más hostiles del continente latinoamericano, convirtiéndose así en una tierra dura para vivir, que obliga a las plantas a crecer con lentitud y a contar con adaptaciones particulares, tanto que, prácticamente no existen plantas ruderales. Finalmente, los suelos son arenosos y pedregosos con escasa materia orgánica, pues la exigua biomasa vegetal se descompone con lentitud. Los horizontes de loess y las morrenas son elementos presentes en numerosos paisajes de la puna, como testigos de glaciaciones pasadas.

\subsubsection{Caracteres geológicos: génesis del altiplano y del conjunto volcánico de Sajama}

Los rasgos físicos de la puna de Sajama vienen marcados por unas formaciones geológicas de naturaleza volcánica, de edad reciente. El PNS alberga interesantes muestras y ejemplos de este tipo de relieves confiriendo al paisaje una identidad muy notable, cuya máxima expresión la otorga el Nevado Sajama (6.542 m).

Diferentes estudios confirman que la gran cordillera de los Andes tiene su origen en la sucesión de tres etapas geológicas:

Una primera, cuyos efectos perduran hoy, coincidente con el fenómeno de subducción de dos placas tectónicas, la placa oceánica del Pacífico o placa de Nazca, y la placa de sudamericana. La subducción, entendiendo este proceso como aquel en el que domina el hundimiento de grandes proporciones de una parte de la litosfera bajo otra, acompañada de una intensa actividad magmática y por otro lado de un engrosamiento y levantamiento de la corteza continental dando lugar al levantamiento de la cordillera de los Andes. Este proceso acontece de forma clara en la fachada occidental del continente latinoamericano desde hace 200 Mill/años aproximadamente, momento en que comenzaron a producirse las primeras erupciones ${ }^{5}$.

(5) Se tiene constancia del inicio de estas primeras manifestaciones magmáticas, que acontecieron en el fondo del mar, como demuestran los depósitos de lavas almohadilladas en la costa chilena. A partir de ese momento y hasta hoy, ese continuo proceso de subducción ha incrementado el espesor de la corteza terrestre en esta zona de contacto, conformando así la cadena montañosa más larga del planeta. Hay quien dice que los volcanes que culminan en esta cordillera no son "la etiqueta, o pequeñas pizcas de crema sobre una inmensa torta de corteza "(Gubbels, et.al. 1993). Resulta interesante cómo, posteriormente, a consecuencia de este aumento de magmatismo se establecieron importantes depósitos de oro, cobre y plata. La acumulación, recalentamiento y precipitado de importantes depósitos de agua situados encima de estas cámaras magmáticas dieron lugar a la localización de importantes yacimientos metálicos, de gran trascendencia para la economia de los paises andinos. 
Una segunda etapa, hace 30 millones de años, en el Oligoceno, en la que tuvo lugar un cambio en la actividad sísmica afectando a la velocidad y ángulo de convergencia del proceso de subducción en la zona de contacto, originando una disminución de la velocidad de empuje de la placa oceánica, que repercutió en la disminución del ángulo de subducción, determinando una mayor y acelerada actividad magmática (Seyfried, 1998). En este periodo, el escudo brasileño cambia su dinámica, siendo más ágil el desplazamiento hacia el oeste o zona de subducción; este doble empuje se estima que favoreció el paulatino engrosamiento de esta cordillera y concretamente la creación de importantes estratovolcanes. Este proceso tuvo importantes consecuencias en la estructura final de los Andes; por un lado, se produce la aparición de fallas que seccionan y delimitan lo que empieza a ser un territorio cordillerano de desniveles desmesurados hacia el Pacífico y, en otro orden de magnitud, hacia el este (interior del continente), empieza a apilarse un elevado volumen de mantos tectónicos. En conclusión, este periodo es el que arma y organiza la cordillera actual haciendo retroceder el arco magmático hacia el este, da lugar a sucesivos mantos de ignimbritas por deposición de nubes ardientes recubriendo todo lo que conocemos como Altiplano (Figura 3).

Una tercera etapa, esencial en la organización andina, viene caracterizada por periodos de actividad volcánica de mucha menor envergadura que ayudaron a incrementar la superficie de ignimbritas por todo el territorio altiplánico. Se tiene constancia hace 6.2 millones de años de la última deposición por nube ardiente, procedente del NE, la conocida Ignimbrita Lauca, de un volumen aproximado de 1000 km³, que se extendió hacia el norte de Chile, canalizándose por las cabeceras de los valles Cardones y Lluta.

La estructura y organización final de los Andes queda definida por una consecución de:
- Alineaciones montañosas y llanuras endorreicas intermedias o "altiplanos", de distinta edad, siendo ésta una de las principales características de las grandes cordilleras.

- Cordillera Costera, formada por materiales de las primeras erupciones volcánicas acontecidas en el fondo del mar.

- Cordillera Principal, también conocida como Cordillera Occidental, que reúne las máximas elevaciones.

- En el interior del continente, una alineación montañosa de menor entidad conocida como Cordillera Oriental, de extensión más reducida.

De forma entrecortada aparecen grandes cuencas subsidentes que han derivado, con el paso del tiempo, en llanuras endorreicas ocupadas hoy por lagos y salares como el lago Titicaca, el Poopó, el salar de Uyuni, o el lago -salar de Coipasa.

\subsubsection{Rasgos orográficos, fisiográficos y morfológicos de la Cordillera Occidental de los Andes}

Desde el punto de vista orográfico, la cordillera Occidental estaría organizada por alineaciones montañosas denominadas nevados y extensas llanuras endorreicas conocidas como pampas o punas.

En lo que respecta a la puna, ocupa un territorio cuya altitud media oscila entre los 3.300 y los 5.000 m. Su extensión abarca desde donde finaliza el páramo peruano 0 Jalca hasta el norte de la provincia de Neuquén en Argentina, donde ya toma el nombre de altipampas o punillas. Esta misma área también recibe el nombre de Meseta del Collao o Meseta del Titicaca; sus límites son algo más extensos ya que abarca la parte occidental de Bolivia, el norte de Chile, el sur del Perú y el norte de Argentina.

En ocasiones se diferencia entre la puna y los llamados altos Andes o región altoandina, debido al relieve llano de la

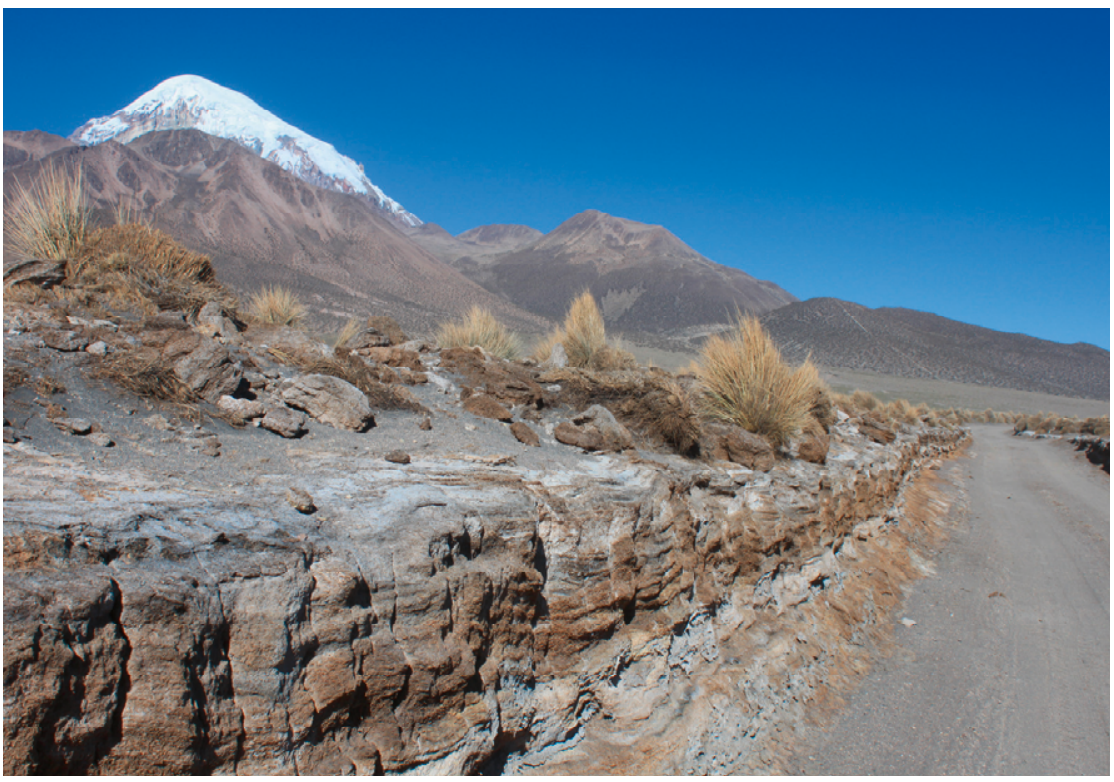

Figura 3. Mantos de ignimbritas por deposición de nubes ardientes provocadas por erupciones volcánicas del Mioceno y Plioceno. Foto del autor. 
primera y con pendientes montañosas del segundo, aunque por lo general si no se especifica, se entiende que la puna incluye ambas hasta la línea de nieves ${ }^{6}$. El territorio de la puna se divide en una serie de cuencas que generan lagunas y salares a veces de grandes proporciones y ríos de poco caudal según el nivel de precipitación, que varía entre los 100 y los $1.500 \mathrm{~mm}$; son los casos del río Lauca, que desemboca en el Salar de Coipasa, y del río Desaguadero, que vierte sus aguas al lago Poopó.

Pese a que en realidad es una transición, estas diferencias han hecho que la puna se divida, según Sánchez (2011) en puna húmeda, situada hacia el norte, con precipitaciones superiores a los $400 \mathrm{~mm}$ e influencia del aire húmedo amazónico, puna de tolas, donde caen menos de $400 \mathrm{~mm}$, con estacionalidad marcada, puna seca, donde caen menos de $150 \mathrm{~mm}$.

Los materiales geológicos que conforman las Ilanuras endorreicas son fundamentalmente detríticos, areniscas, argilitas, conglomerados, yesos y cenizas volcánicas, restos de antiguas cordilleras y de la paulatina evolución y destrucción de materiales de origen volcánico pertenecientes a numerosas formaciones litoestratigráficas (ver figura 4).

Generalmente estos materiales se encuentran horizontales o ligeramente plegados, constituyendo relieves 0 pequeñas serranías altiplánicas y áreas de colinas muy disectadas producto de la erosión diferencial. Acompañando a estos materiales encontrarían litologías más recientes, destacando entre las más importantes las litologías volcánicas que conforman los estratovolcanes, conos y hornitos volcánicos menores de edad miocena (nevado Anallajchi) y pliocena (Sajama y Payachatas). También hay que tener en cuenta otros materiales de naturaleza sedimentaria, por deposición fluvio-lacustre, como arenas, arcillas, limos y evaporitas holocenas, dispuestos de forma horizontal con ausencia de plegamiento, configurando áreas de topografía plana.

La acción erosiva sobre estos materiales es la que configura y da forma a este paisaje de alta montaña árida protagonizado por un rosario de morfologías desnudas y carentes de vegetación y que a continuación se resume:

- Cordilleras: en su conjunto aparecen formadas por materiales volcánicos, ignimbritas, riodacitas y lavas andesitico-dacíticas; las primeras generalmente constituyen mesetas y las segundas, edificios volcánicos y coladas lávicas.

- Formas glaciares: en las altas cumbres encontramos la acumulación de fragmentos heterogéneos de roca transportados por la acción glaciar, la retirada de estos aparatos ha dado lugar a la aparición de importantes morrenas y valles en forma de artesa.

- Glacis detríticos: constituyen unidades de gran entidad que enlazan mediante suaves rampas, los nevados, cerros o serranías con las depresiones fluvio-lacustres. En Sajama esta forma de relieve se origina a partir de la acu-

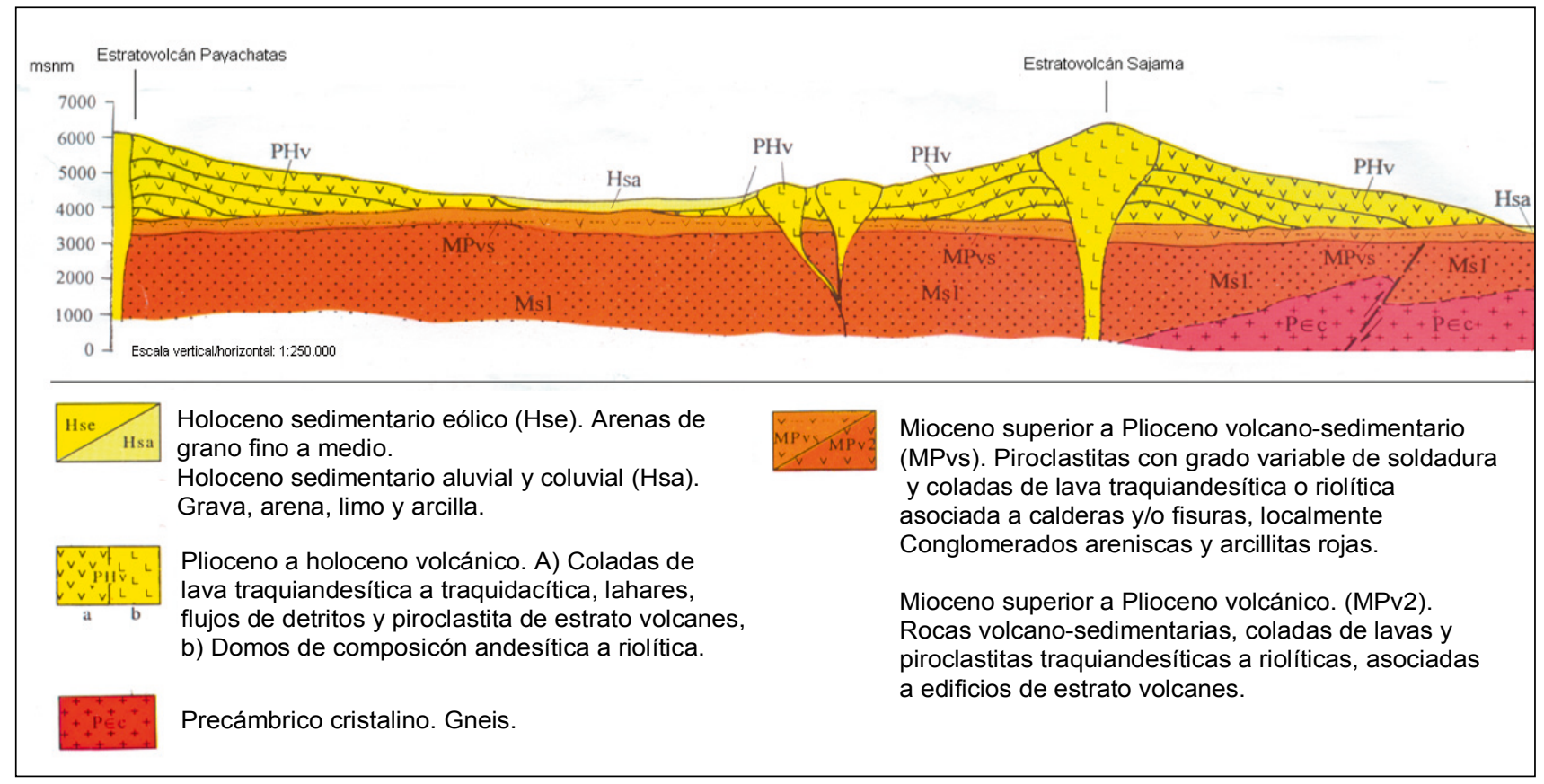

\ FIguRa 4. Esquema geológico Altiplano de Sajama. Fuente: Thematic maps of mineral resoruces of Bolivia. (1995). Swedish geological Ab., Suecia./Servicio Geológico de Bolivia.

(6) Beck y García (1991) definieron la zona altoandina como la que está por encima del límite de los árboles, pero como se apunta en el texto, existen bosques a $5.300 \mathrm{~m}$ y no conocemos con precisión sus límites altitudinales en el pasado. 


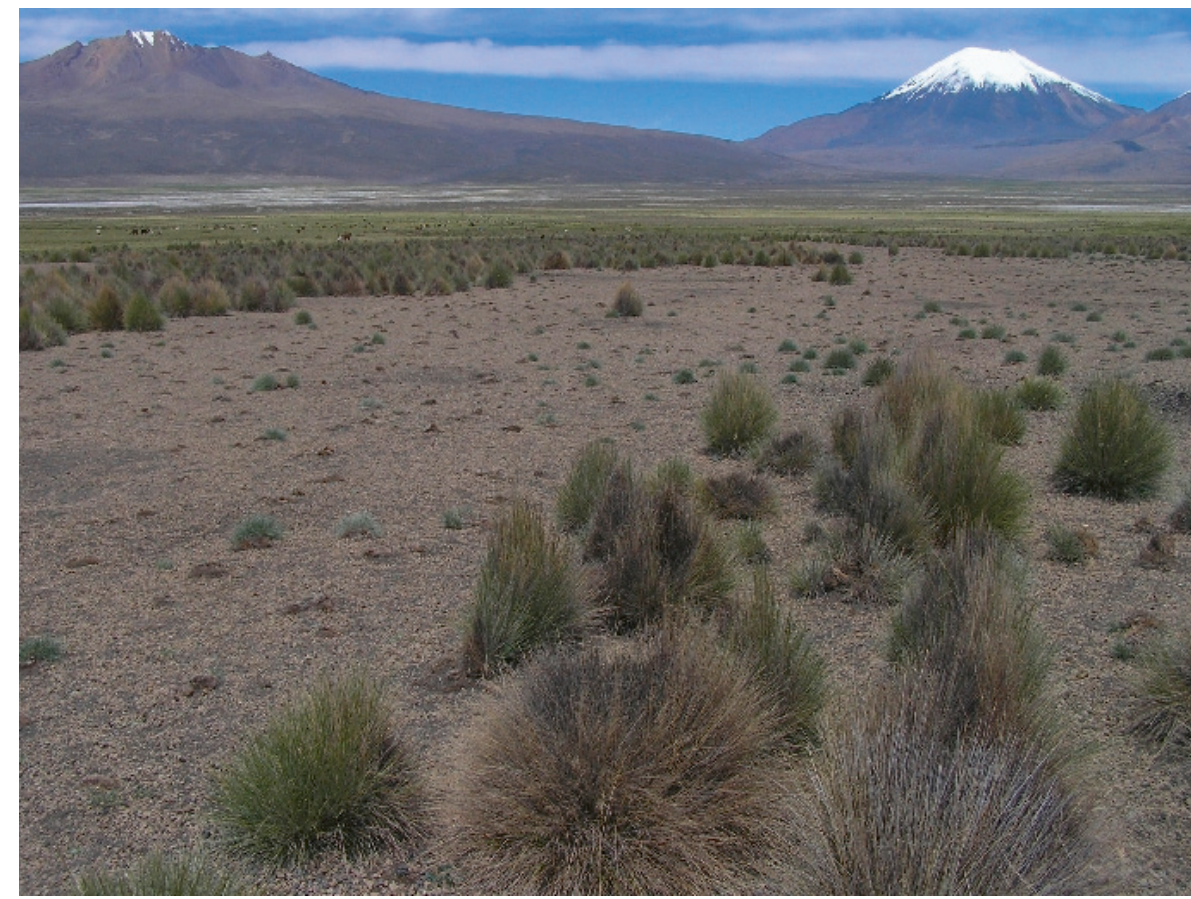

4 FiguRA 5. Alineaciones montañosas y llanuras endorreicas intermedias o "altiplanos". Foto del autor.

mulación de derrubios procedentes de la criogénesis de los materiales de zonas más elevadas, originando extensos glacis o pediment.

- Llanuras fluvio-lacustres endorreicas: formadas por una amplia variedad de morfologías que dan lugar a la existencia de playas lacustres, terrazas fluviales, bofedales y salares principalmente.

\subsubsection{Caracteres climáticos}

Sajama se encuentra dentro de la Micro Región conocida como Occidental, donde se pueden diferenciar hasta tres pisos bioclimáticos: orotropical, criorotropical y atérmico. La característica fundamental entre estas tres franjas reside en un descenso de la temperatura desde las áreas bajas de pampa situadas a $4.000 \mathrm{~m}$ hasta zonas por encima de los $5.500 \mathrm{~m}$, donde las precipitaciones y la acumulación de nieve y hielo dan lugar a nieves perpetuas y a la generación de sistemas glaciares.

Tomamos la estación meteorológica de la población de Sajama como observatorio de referencia. Una temperatura media anual de $4,3{ }^{\circ} \mathrm{C}$ y una precipitación media

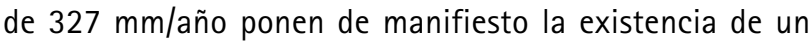
clima extremadamente frío y árido al no existir apenas periodos importantes de precipitaciones. El verano, de noviembre a febrero, es el periodo menos frío, llegando a una media de $6,8{ }^{\circ} \mathrm{C}$ para el mes de noviembre, mientras que en el solsticio de invierno, de junio a septiembre, se pueden registrar medias en torno a $1^{\circ}$ y $3{ }^{\circ} \mathrm{C}$.

A escala local y sobre la base del estudio de las interrelaciones entre topografía y clima, en el área de estudio se distingue la presencia de un topoclima caracterizado por una amplitud térmica diaria muy fuerte, en ocasiones su- pera los $40{ }^{\circ} \mathrm{C}$, provocando un estado de stress ambiental manifiesto en la cubierta vegetal existente, con predominio de una flora de escaso porte con consecuencias sobre la dinámica geomorfológica al abundar los procesos de meteorización física, y desde el punto de vista humano, unas formas de ocupación, de hábitat y de aprovechamiento muy limitados.

Los vientos son un rasgo de este medio andino, no tanto las corrientes dominantes que proceden del oeste sino los vientos locales o brisas de montaña, que afectan principalmente a zonas bajas donde se localizan las poblaciones. La existencia de estos vientos de carácter local depende en gran medida de la topografía y las variaciones de temperatura. De este modo, los vientos adiabáticos cuyo funcionamiento se instala a primeras horas del día, conlleva la presencia de rachas fuertes únicamente en zonas de cumbres afectando tan solo a algunas estancias por encima de los $5.000 \mathrm{~m}$. Por su parte, los vientos catabáticos, procedentes de las zonas elevadas hacia los valles (Aguilera et al, 2009), sacuden durante la tarde las Ilanuras y pampas dificultando enormemente la vida de las principales poblaciones, como ocurre en Lagunas, Sajama y Tomarapi, y en el conjunto de estancias dispersas por la puna.

Durante los meses de noviembre a marzo, tienen lugar las escasas precipitaciones que se registran, mientras que los meses de otoño e invierno corresponden al periodo de seco.

Resumiendo y de acuerdo con las características indicadas y aplicando la clasificación propuesta por Köppen, la región de Sajama cuenta con dos tipos diferentes de clima:

- Clima Estepario (BS) Semiárido. Clima caracterizado por lluvias escasas e irregulares repartidas durante 


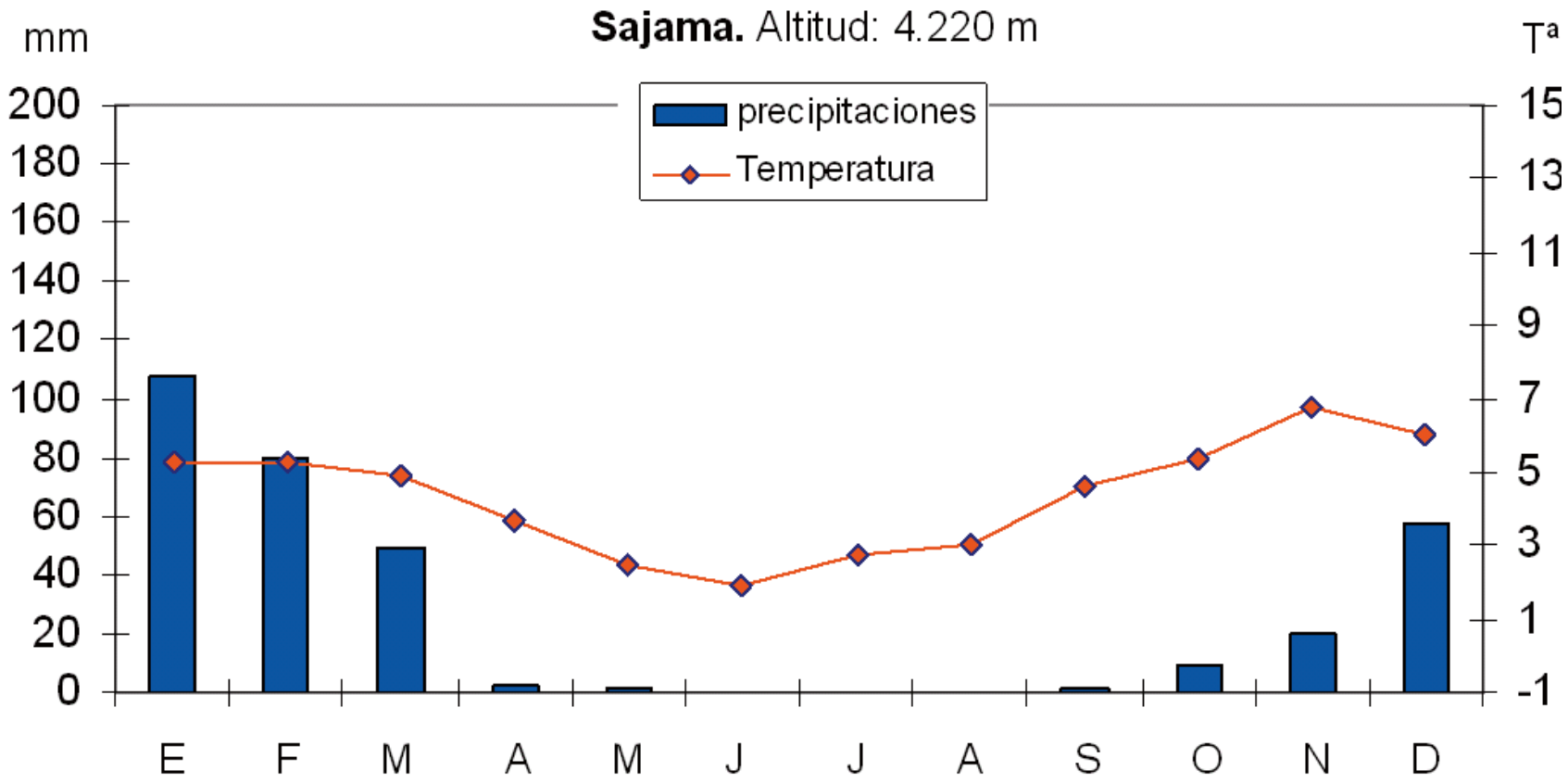

ム Figura 6. Climodiagrama de Sajama. Fuente: Elaboración propia.

los meses de ocubre a marzo, con un máximo en el mes de enero $(108 \mathrm{~mm}$ ) y total ausencia de precipitaciones en los meses de junio a agosto. La evapotranspiración potencial supera a la preciptación pero no la dobla $(567,46 \mathrm{~mm}$ según fórmula de Patton). Como consecuencia de estos factores el aire resulta extremadamente seco, cuya humedad relativa es del 47,7\%. Las pampas de Sajama, Tomarapi e Isquillani, asi como el resto de áreas de la cuenca del río Lauca, sufren fuertes oscilaciones térmicas diarias, superiores a los $35^{\circ} \mathrm{C}$. Los vientos resultan secos y en combinación con los vientos catabáticos procedentes de las quebradas y nevados juegan un papel importante en la evaporación y en la áridez. En Bolivia encontramos este clima en el ángulo sudoeste del altiplano, afectando a las grandes llanuras y pampas donde se practica la ganadería de camélidos.

- Clima de Montaña (H). Se caracteriza por disminuir la temperatura con la altura por tanto, existen temperaturas más bajas que las de las tierras próximas menos elevadas. Fuertes oscilaciones térmicas diarias, gradiente térmico irregular, más elevado en verano que en invierno. Diferencias térmicas según la posición entre solana y umbría. Desde el punto de vista pluviométrico, las precipitaciones son mayores que en las pampas y zonas bajas. El regimen estacional de precipitaciones es más regular 0 , por lo menos, menos contrastado que en los valles. Son significativas las precipitaciones en forma de nieve manifiestas a lo largo de todo el año, cumbres del Nevado Sajama, Payachatas y Nevados Condoriris. Este tipo de clima se encuentra en las Cordilleras Occidental y Oriental de los Andes, regiones donde la nieve.
A continuación se presenta una tabla con los registros de la estación meteorológica Sajama, ubicada dentro del parque y cuyos datos pertenecen al periodo 1960-1990.

Los riesgos climáticos derivados de un clima extremointensas nevadas, fuertes Iluvias, etc., suponen un obstáculo para el óptimo desarrollo de la agricultura y ganadería, también para el turismo, al limitarse el número de actividades y la duración de éstas.

\section{Los nevados y su peculiar modelado glaciar}

Los grandes glaciares tropicales quedan relegados a las más altas e importantes alineaciones de los Andes, como la Cordillera Blanca en el Perú o la Real en Bolivia. En Sajama, la acumulación de nieve tiene lugar de una forma muy peculiar, pues se concentra en una única temporada que coincide con la más cálida, meses de diciembre a marzo. Como resultado de la precipitación de nieve estival, la elevadísima radiación, y del acentuado contraste térmico entre el día y la noche, se originan morfologías glaciares como cornisas apelmazadas, paredes estriadas y caprichosas formas en el hielo conocidas como penitentes configuran un paisaje de montaña casi único en el mundo.

En los Andes son significativos los glaciares que varian sustancialmente en función de su posición latitudinal, altitud y ubicación geográfica instalados en los altos volcanes ecuatoriales. Así, por las laderas de los diferentes nevados -Sajama, Payachatas, Condoriris, Quisi Quisini y Anallajsidesciendieron en tiempos pretéritos importantes lenguas glaciares de época pleistocena. La diferente fisonomía de 


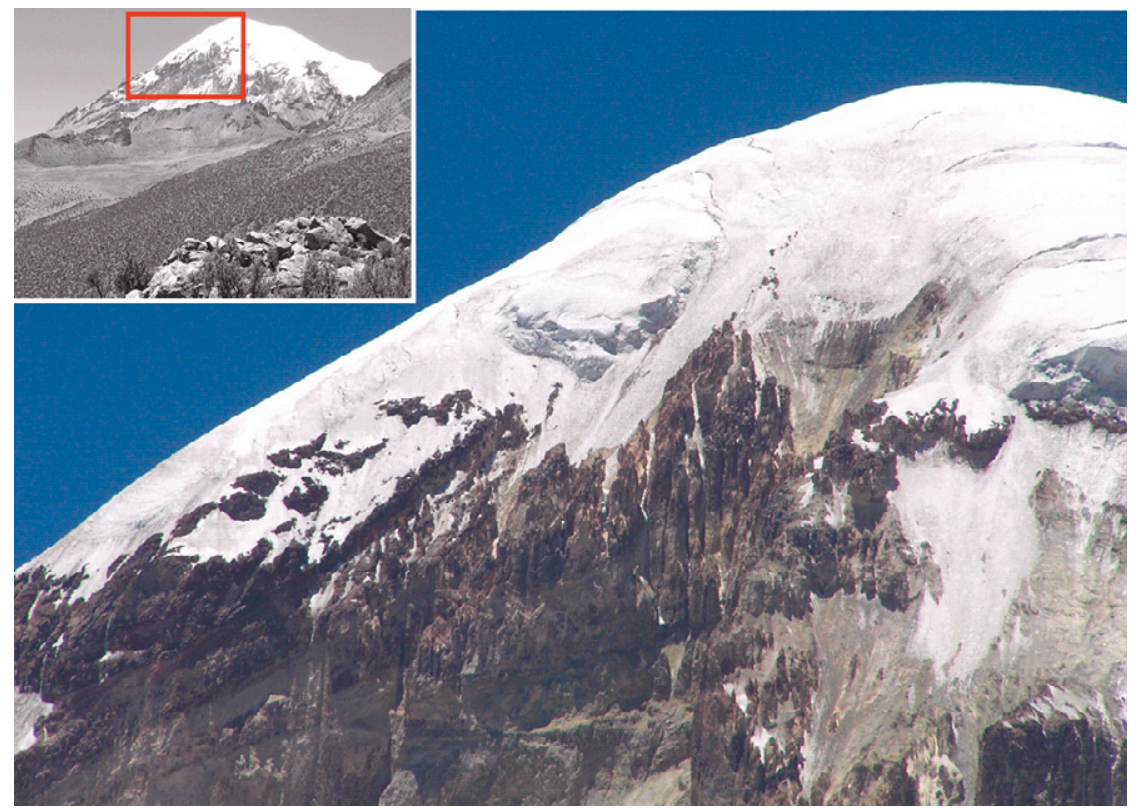

Figura 7. Cornisas y paredes glaciares. Nevado Sajama. Foto del autor.

estos nevados dio lugar a la aparición de dos tipos de glaciares:

- Glaciares de cúpula, localizados en los nevados más recientes (Plioceno), caso de Sajama; se caracterizaron por evacuar el hielo de forma extrusiva, mediante múltiples lenguas dispuestas de forma concéntrica.

- Glaciares de montaña o de valle, se diferencian de los anteriores por la existencia de dos zonas de ablación: la cuenca o cabecera de acumulación, y el valle por donde circularon largas lenguas de descarga.

En ambos casos, las masas de hielo procedentes de las cumbres alcanzaron cotas bastante bajas. En la actualidad puede observarse la herencia de estos glaciares, que dieron forma, en su paulatino retroceso en el periodo interglaciar (Holoceno), a valles de fondo plano, crestas morrénicas, morrenas laterales y zonas de acumulación.

\subsubsection{Caracteres edáficos}

Los suelos existentes en el altiplano de Sajama corresponden a tierras arables de las clases II a IV según la clasificación de la Soil Conservation Service, siendo muy abundantes los suelos de clase IV, compuestos por unos horizontes con limitaciones permanentes y severas para el cultivo. Los suelos de esta última tipología presentan características desfavorables para el cultivo, con frecuencia se hallan en pendientes fuertes sometidos a erosión

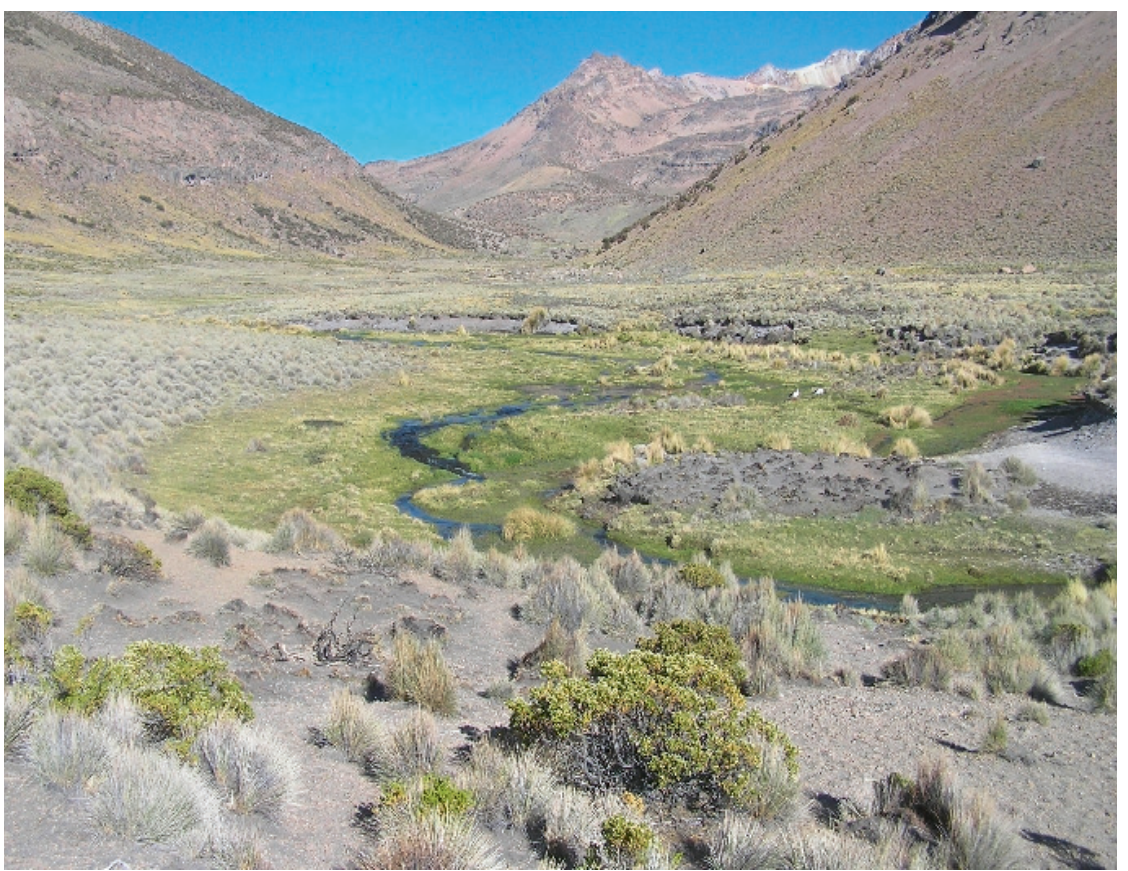

Figura 8. Valle glaciar de Junthuma. Foto del autor. 
intensa. Su adecuación para ser cultivados es muy limitada, generalmente deben ser destinados a pastos, aunque puede obtenerse de ellos una cosecha de grano cada cinco o seis años. En el PNS esta clase de suelos pobres se asienta en áreas de terraza y meseta volcánica y en depresiones salinas y bofedales. Incluyen en muchos casos acumulaciones eólicas, depósitos de vertiente y abundantes piedras procedentes de la actividad glaciar, limitando así el uso silvopastoril intensivo, destinándose exclusivamente al pastoreo de camélidos y/o ovinos, especialmente en zonas de bofedal.

En lo que respecta a la salinización, cerca de $3.449 \mathrm{~km}^{2}$ correspondientes al 2,4\% de los terrenos de la región han sido clasificados como tierras salinas, localizándose la mayor parte de ellas alrededor del salar de Coipasa y del lago Poopó y su alta salinidad de debe básicamente a las inundaciones de los ríos Desaguadero, Lauca y su posterior evaporación.

\subsubsection{Caracteres hidrogeográficos}

Las nieves perpetuas del gran Nevado Sajama y del resto de nevados proporcionan caudal a tres rios de cierta entidad, el Sajama, el Isquillani y el Tomarapi, afluentes del río Lauca $^{7}$, que desemboca en el lago y salar de Coipasa, a 3.653 m. Tanto el Sajama como el Lauca y sus tributarios forman parte del sistema endorreico Titicaca-Desaguadero-Poopósalar de Coipasa, que se extiende desde el sur del Perú hacia el sur de la meseta del Collao en la frontera chilena. Este sistema destaca por la presencia de varias cuencas endorreicas constituidas por lagunas o salares menores nacidos de manantiales en la base de los nevados de la Cordillera Occidental.

En lo que respecta a la hidrodinámica de estas aguas, en primer lugar la composición hidroquímica muestra un alto grado de mineralización producto de manifestaciones geotérmicas. Por otro lado, la evolución ecológica de la cuenca

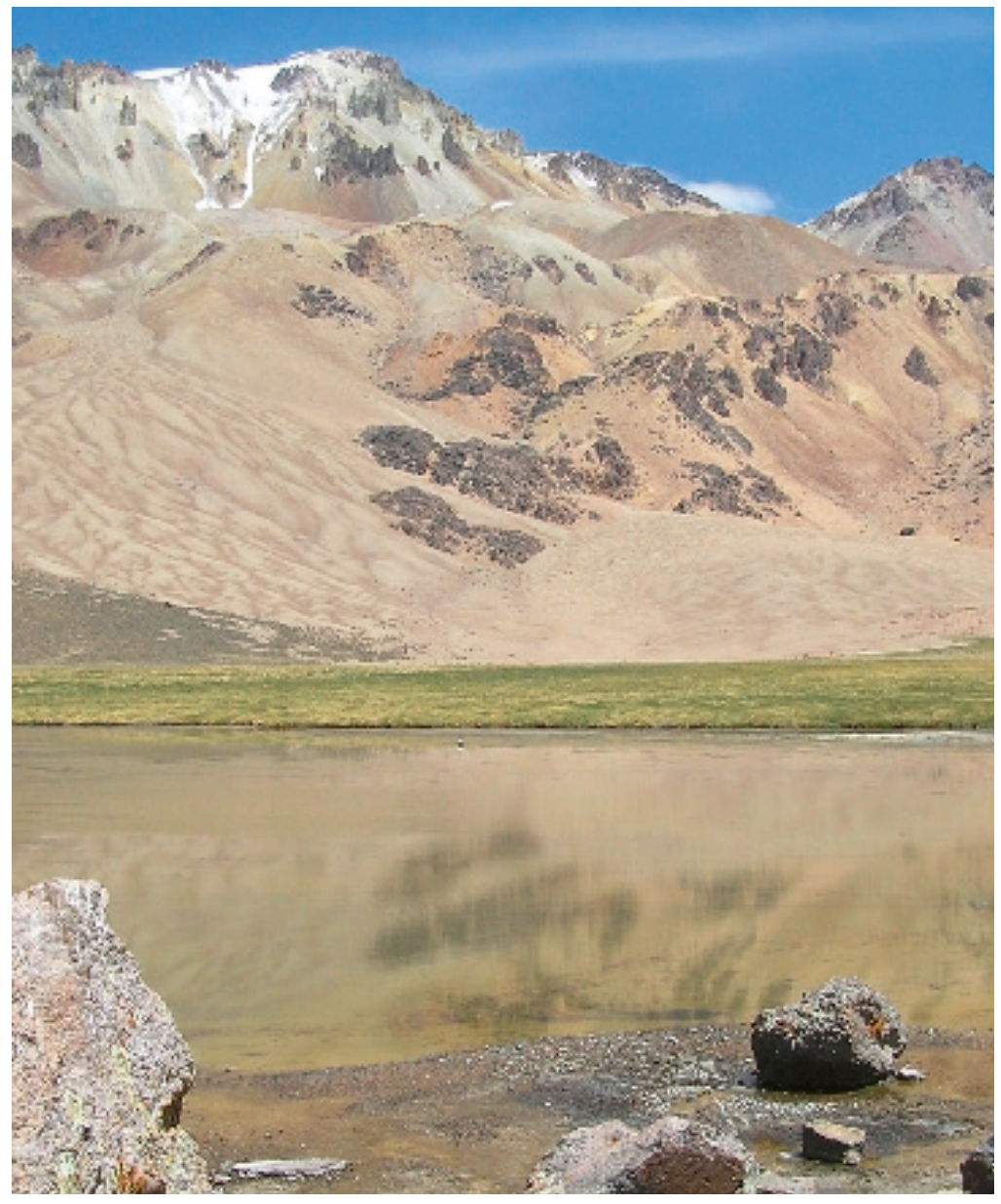

FIGURA 8. Valle glaciar de Junthuma. Foto del autor.

(7) Río Lauca, del vocablo aimara lawqa, que significa "pasto acuático", recibe aportes de diversos cursos, como el río Sajama y el río Copasa. Durante los años 1930, el gobierno chileno comenzó a utilizar los recursos hídricos del río Lauca para el regadío agrícola de la zona del valle de Azapa, lo que motivó el reclamo del gobierno boliviano, asegurando que las autoridades trasandinas estarian desviando un río de aguas internacionales. Puede ser éste uno de los motivos que empujaron al gobierno de Bolivia a la declaración del Parque Nacional Sajama en el año 1939. Chile argumentó que no se realizaban desvios del cauce natural sino que los trabajos se referian a utilización de aguas en las zonas del bofedal de Parinacota, lo que no afectaba al caudal total del Lauca en su paso a Bolivia. El litigio entre ambos paises, iniciado en 1939 (fecha de declaración del Parque Nacional Sajama), provocó momentos de gran tensión diplomática hasta los años 1960. 
hidrográfica asiste a un gradual proceso de desertificación, debido en gran medida a la salinidad y mineralización de las cuencas que la componen, como sucede en el caso del río Sajama y sus afluentes, cada vez más salinizados, a las extremadas condiciones de aridez, naturaleza volcánica y a la soprexplotación de los recursos pascícolas en sus zonas de cabecera. Así, sirva de ejemplo la meseta del Collao, donde se asientan el salar de Uyuni y el salar de Coipasa, que reciben aguas salobres de sus afluentes, el río Grande de Lipez y el Pucamayu hacia el Uyuni y Rio Lauca y Lacajahuira hacia Coipasa. Asimismo el lago Poopó y el lago Uru Uru contienen aguas altamente mineralizadas que aceleran el proceso de convertirse en salares. De la misma manera el río Desaguadero recibe el aporte de aguas mineralizadas del río Maure, por lo que el aporte del lago Titicaca hacia el sur de la cuenca se vuelve fundamental para la subsistencia de la agricultura en la región meridional de la meseta.

En general, los ríos que recorren la puna de Sajama destacan por ser meandriformes en sus cuencas medias e inferiores debido a la muy escasa pendiente y al arrastre continuo de sedimentación procedente de las cabeceras de litología volcánica ${ }^{8}$.

Esta dinámica da lugar a distintos fenómenos, el más común en la zona es la aparición de zonas húmedas o bofedales, coincidentes con la salida de los cursos después de los tramos de mayor pendiente y angostura; aquí el caudal invierte su energía, convirtiéndose en un río tranquilo y en algunos tramos, divagante. En otros casos, el escaso caudal y la ya citada ausencia de pendiente, obliga a que estos cursos se paralicen, no pudiendo alcanzar su desembocadura "normal", originando lagunas y reducidos salares por evaporación como la laguna Kellua Kota, la laguna Isla y la laguna Huaña Khota, el mayor humedal del parque con 68 $\mathrm{Ha}$. Las lagunas de origen glaciar se encuentran en la cabecera de estas cuencas, como sucede con Chiar Khota, situada a $5.000 \mathrm{~m}$, bajo los nevados Condoriris, perteneciente a la cuenca del río Sajama. Al norte del parque se encuentran Uskha y Khashi de 2,7 y $2 \mathrm{Ha}$ respectivamente. Existen otras de menor tamaño situadas a mayor altitud, cuyo origen es igualmente glaciar.

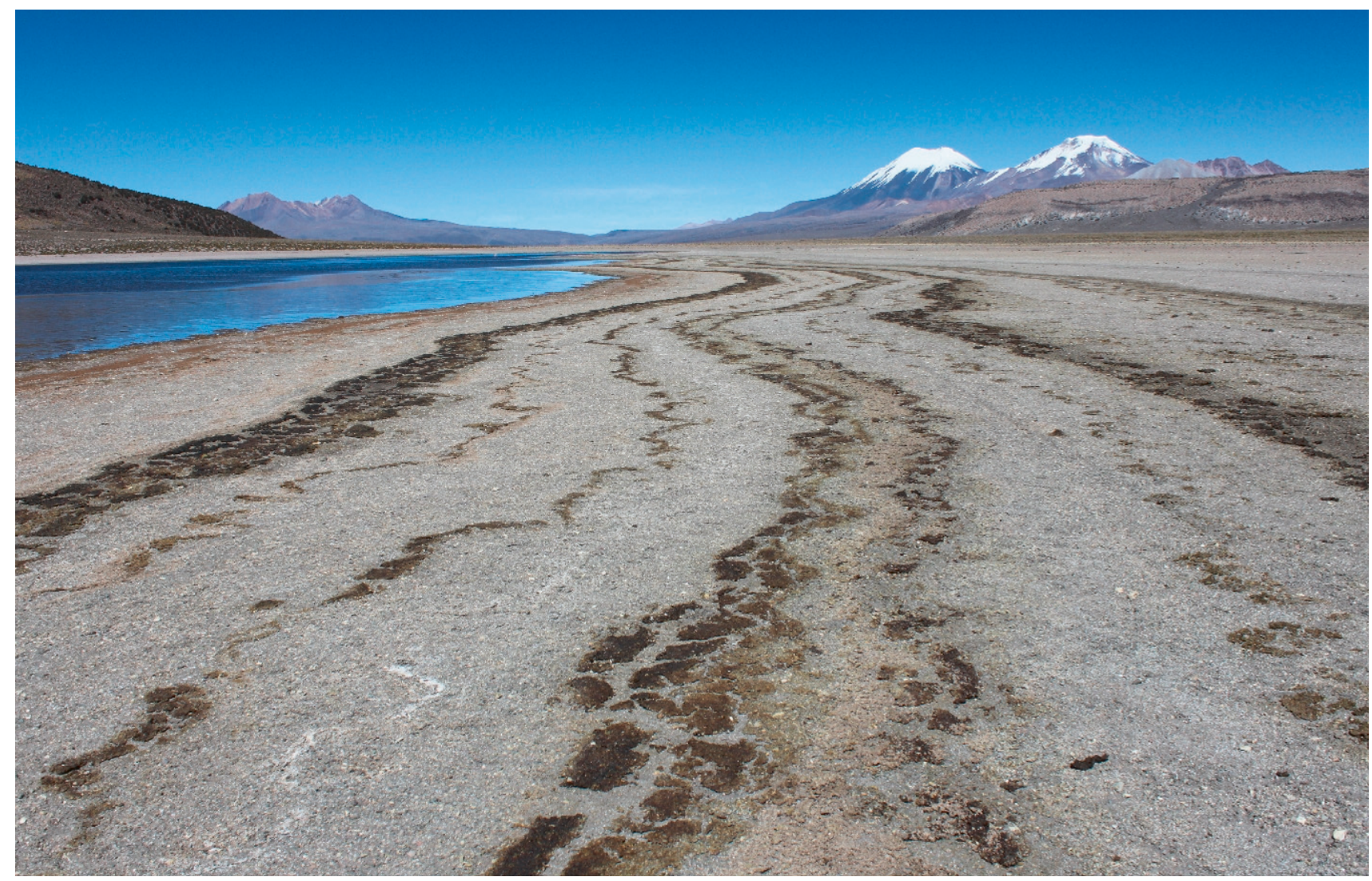

A Figura 9. La topografía plana y el escaso caudal de los ríos que recorren las pampas favorecen la creación de lagunas y salares. Laguna Huaña Khota. Foto del autor.

${ }^{(8)}$ Los ríos de la Cordillera Occidental al salir de las quebradas inician un curso meandriforme por materiales de naturaleza volcánica muy deleznables. Los nevados Sajama y Payachatas encuentran en su base un importante espesor de mantos de ignimbritas de naturaleza piroclástica arrojadas por estos volcanes en forma de nube ardiente. Estas rocas están formadas por fragmentos y cascos de vidrio colocados en bandas, bien definidas apareciendo como fragmentos aplanados. La fácil erosionabilidad de esta litología motiva el curso meandriforme y en consecuencia el arrastre de terrigenos hacia los tramos medios acelerándose asi el proceso de endorreísmo tan acusado en la meseta del Collao. 


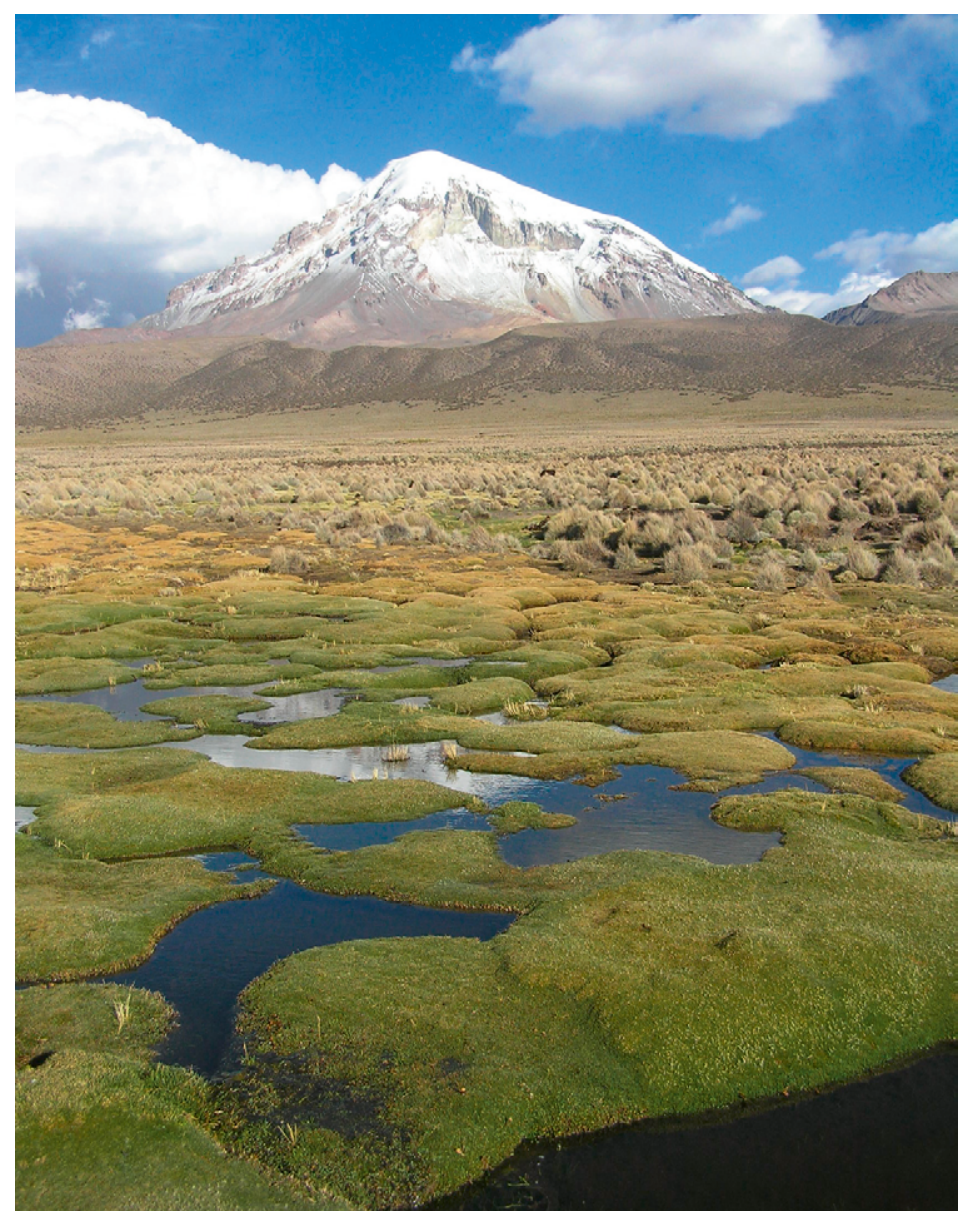

FIGURA 10. Bofedal estacionalmente inundado formado por cojines compactos aislados de Scirpetum deserticotae separados por microcaudales, al fondo nevado Sajama. Foto del autor.

Vinculadas a la actividad volcánica de la zona, existen aguas termales y pequeños géiseres asociados a puntos y alineaciones calientes situados en los valles y planicies.

\subsubsection{Caracteres biogeográficos}

El paisaje de la puna de Sajama encuentra en sus caracteristicas biogeográficas y, particularmente, fitogeográficas un componente muy importante de su diversidad morfológica, ecológica y estética. Tales caracteristicas obedecen a los rasgos de relieve y clima ya comentados, y a la secular acción humana. Los rasgos climáticos antes presentados son responsables de la existencia de una serie de áreas muy contrastadas, como los cinturones de bosque o queñual en las vertientes de los nevados, las manchas de tholar y pajonal del fondo de valle, junto a zonas de desierto de altura, donde persisten formaciones vegetales ralas adaptadas a los rigores de la altitud y la aridez extrema. Por otra parte, las actividades humanas y el manejo de los recursos naturales, praderas y bosques, terminan configurando un mosaico vegetal que se aleja bastante de la imagen y dinámica natural que correspondería desde un punto de vista potencial.

Biogeograficamente el PNS está incluido, según la clasificación establecida por Navarro y Maldonado (2002), dentro de la provincia biogeográfica altiplánica, extendida por el suroeste de los Andes de Perú, Cordillera Occidental, altiplano de Bolivia, noreste de Chile y noreste de Argentina.

Debido a la gran extensión que ocupa esta provincia se han diferenciado tres sectores, establecidos de acuerdo con las condiciones climáticas, concretamente temperatura y precipitaciones.

- Sector biogeográfico Norte Altiplánico. El límite septentrional se sitúa en el extremo sur de Arequipa (Perú) hasta los $19^{\circ} \mathrm{S}$ aproximadamente de latitud, hacia el este continúa por el cordón de Sabaya (Bolivia), cuenca media y baja del río Lauca, norte del salar de Coipasa hasta el sur del lago Poopó. Clima xérico con una precipitación anual media de entre $200-450 \mathrm{~mm}$.

- Sector biogeográfico Centro Altiplánico. Hacia el norte limita con el sector norte Altiplánico alcanzando los $19^{\circ} \mathrm{S}$, extendiéndose por las cuencas de los grandes salares altiplánicos y por las altas cordilleras de Sud Lipez occidental boliviano y montañas adyacentes de Chile y Argentina hasta unos $25^{\circ} \mathrm{S}$. Su bioclima es xérico inferior a semiárido en las altas montañas y altiplano, y árido en el piso supratropical de las vertientes que vierten hacia el $\mathrm{Pa}-$ cífico, con una precipitación media anual inferior a $300 \mathrm{~mm}$.

- Sector biogeográfico Sur Altiplánico. Presente únicamente en el territorio argentino, localizado a unos $25^{\circ} \mathrm{S}$ 
aproximadamente, prolongándose hasta las altas cordilleras tropicales del sur de La Rioja y norte de San Juan. En este sector se da cita una flora peculiar donde son comunes géneros con óptimo austral mediterráneo (Mesochileno-Patagónico).

\section{La cubierta vegetal del Parque Naciona/Sajama}

Las diferentes asociaciones vegetales y los complejos patrones de uso humano tradicional del territorio en el altiplano de Sajama configuran un cubierta vegetal muy singular, diferente al de otras zonas próximas y de iguales características climáticas.

En el área de estudio hay que distinguir dos pisos ecológicos, el piso orotropical y el criorotropical. En la tabla que se incluye a continuación figura una caracterización sintética de la vegetación existente en el parque, con datos sobre su localización, especies y comentarios sobre el estado de conservación. 


\begin{tabular}{|c|c|c|c|c|}
\hline PISO BIOCLIMÁTICO & \multicolumn{4}{|c|}{ CARACTERÍSTICAS } \\
\hline $\begin{array}{c}\text { PISO } \\
\text { OROTROPICAL }\end{array}$ & \multicolumn{4}{|c|}{$\begin{array}{l}\text { Perteneciente a la provincia o región biogeográfica Altiplánica. } \\
\text { Formación más representativa: bosque de keñua que ocupa las faldas de los cerros y nevados en forma } \\
\text { de cinturones arbóreos. } \\
\text { En zonas bajas predominio del matorral serial, tholar y pajonal. }\end{array}$} \\
\hline Formación & Situación & $\begin{array}{l}\text { Características } \\
\text { de la formación }\end{array}$ & Especies & Grado de conservación \\
\hline Bosque de queñua & $\begin{array}{l}\text { - De forma aislada } \\
\text { y dispersa en } \\
\text { laderas y vertientes, } \\
\text { en glacis, cerros y } \\
\text { serranías volcánicas } \\
\text { y altas mesetas de } \\
\text { ignimbríticas. } \\
\text { - Suelos bien } \\
\text { drenados y a una } \\
\text { altitud media de } \\
4.200 \text { m alcanzando } \\
\text { cotas de } 5.500 \text { m. }\end{array}$ & $\begin{array}{l}\text { - Microbosque } \\
\text { o arbusteda } \\
\text { sempervirente, } \\
\text { de } 1.5-3 \text { m de } \\
\text { porte arbóreo, } \\
\text { estacional, micrófilo } \\
\text { y subesclerofilo, } \\
\text { que constituye la } \\
\text { vegetación potencial } \\
\text { de carácter } \\
\text { climatófilo. } \\
\text { - Se desarrolla } \\
\text { sobre suelos } \\
\text { cambisoles distrito- } \\
\text { húmicos, andosoles } \\
\text { úmbricos y } \\
\text { leptosoles úmbricos. } \\
\text { - El humus que } \\
\text { genera este bosque } \\
\text { es del tipo mör- } \\
\text { tängel-mörder, } \\
\text { caracterizado por } \\
\text { su lenta y mala } \\
\text { descomposición. }\end{array}$ & $\begin{array}{l}\text { Polylepis } \\
\text { tarapacana } \\
\text { Azorella compacta } \\
\text { Baccharis incarum } \\
\text { Chersodoma } \\
\text { jodopappa } \\
\text { Mutisa manigera } \\
\text { Senecio neeanus } \\
\text { Senecio spp. } \\
\text { Lupinus spp. }\end{array}$ & $\begin{array}{l}\text { - Muy transformado e intervenido por } \\
\text { el hombre. } \\
\text { - Gracias a la declaración de } \\
\text { Parque Nacional y a las políticas de } \\
\text { conservación, las escasas áreas en donde } \\
\text { aún persiste evolucionan de forma } \\
\text { favorable. } \\
\text { - El avance de esta formación permite } \\
\text { a su vez la recuperación de hábitats } \\
\text { faunísticos muy amenazados como el } \\
\text { puma. } \\
\text { - En grandes extensiones estos bosques } \\
\text { han sido alterados por la acción humana } \\
\text { (carboneo, minería, etc.), dando paso a } \\
\text { otro tipo de formaciones como el tholar. }\end{array}$ \\
\hline Tholar & $\begin{array}{l}\text { - Partes bajas de } \\
\text { laderas y mesetas, } \\
\text { fronteriza con el } \\
\text { pajonal. } \\
\text { - En franjas } \\
\text { altitudinales en } \\
\text { torno a los } 4.200 \text { - } \\
4.500 \mathrm{~m} \text {. }\end{array}$ & $\begin{array}{l}\text { - Formación } \\
\text { de matorral } \\
\text { permanentemente } \\
\text { verde de } 0,5-1 \mathrm{~m} \text { de } \\
\text { dosel. }\end{array}$ & $\begin{array}{l}\text { Parastrephia } \\
\text { quadrangularis), } \\
\text { Senecio spp. } \\
\text { Adesmia } \\
\text { spinosissima } \\
\text { Calceolaria } \\
\text { inamoena } \\
\text { Parastrephia lucida }\end{array}$ & - Bien conservados \\
\hline Pajonal & $\begin{array}{l}\text { - En márgenes de } \\
\text { vegas limitando con } \\
\text { áreas de bofedal y } \\
\text { tholar. } \\
\text { - En zonas altas } \\
\text { entrando en } \\
\text { contacto con los } \\
\text { glacis. }\end{array}$ & $\begin{array}{l}\text { - Formación } \\
\text { herbácea } \\
\text { densa hidrófila, } \\
\text { sobre suelos } \\
\text { estacionalmente } \\
\text { saturados de } \\
\text { humedad, de } \\
\text { carácter eútrofo. }\end{array}$ & $\begin{array}{l}\text { Deyeuxia curvula } \\
\text { Deyeuxia rigescens } \\
\text { Astralagus spp. } \\
\text { Arenaria boliviana } \\
\text { Festuca orthophylla } \\
\text { Lachemilla pinnata } \\
\text { Quinchamalium } \\
\text { procumbens }\end{array}$ & $\begin{array}{l}\text { - Bien conservados } \\
\text { En determinadas áreas se encuentra muy } \\
\text { degradado debido a las roturaciones y } \\
\text { quemas provocadas por ganaderos. } \\
\text { - El aumento de la cabaña ganadera } \\
\text { ha provocado un retroceso de este tipo } \\
\text { de formación en algunos sectores del } \\
\text { Parque debido a la sobrecompactación } \\
\text { provocada por la pernoctación de llamas } \\
\text { y alpacas. }\end{array}$ \\
\hline
\end{tabular}




\begin{tabular}{|c|c|c|c|c|}
\hline PISO BIOCLIMÁTICO & \multicolumn{4}{|c|}{ CARACTERÍSTICAS } \\
\hline Bofedal & $\begin{array}{l}\text { - En áreas donde } \\
\text { existe un aporte } \\
\text { continuo de agua. } \\
\text { - Formación } \\
\text { compuesta por } \\
\text { multitud de } \\
\text { herbáceas en zonas } \\
\text { de fondo de valle y } \\
\text { vegas. } \\
\text { - En determinados } \\
\text { casos en áreas } \\
\text { anegadas por } \\
\text { constante } \\
\text { presencia de agua } \\
\text { mineralizada y } \\
\text { no mineralizada, } \\
\text { procedente en gran } \\
\text { parte de surgencias } \\
\text { termales. } \\
\text { - En depresiones } \\
\text { y fondos de valle } \\
\text { glaciar, en torno a } \\
\text { los } 4.000 \text { m hasta los } \\
4.600 \text { m de altitud. }\end{array}$ & $\begin{array}{l}\text { - Las distintas } \\
\text { variedades } \\
\text { de bofedal se } \\
\text { caracterizan } \\
\text { por adoptar } \\
\text { una morfología } \\
\text { generalmente plana, } \\
\text { o ligeramente } \\
\text { abombada a } \\
\text { partir de cojines } \\
\text { compactos, aislados } \\
\text { unos de otros y } \\
\text { separados por una } \\
\text { lámina de agua } \\
\text { fluctuante de forma } \\
\text { estacional. } \\
\text { - Cualquiera de } \\
\text { las variedades } \\
\text { que existen es } \\
\text { aprovechada por el } \\
\text { ganado camélido; } \\
\text { llamas, alpacas } \\
\text { y zonas elevadas } \\
\text { vicuñas. }\end{array}$ & $\begin{array}{l}\text { (Distichia } \\
\text { muscoides } \\
\text { Scirpetum } \\
\text { deserticotae } \\
\text { Oxichloe andina } \\
\text { Azorella biloba } \\
\text { Liliopsis macloviana } \\
\text { Cotula mexicana } \\
\text { Hypochoeris } \\
\text { taraxacoides } \\
\text { Genciana desifolia } \\
\text { Plantado tubulosa } \\
\text { Lachemilla } \\
\text { diplophylla }\end{array}$ & $\begin{array}{l}\text { - Muy degradado } \\
\text { - Altamente intervenido. } \\
\text { - En general los tres variedades } \\
\text { de bofedal se encuentran muy } \\
\text { transformadas por la actividad ganadera, } \\
\text { no obstante se observan diferencias } \\
\text { entre aquellos bofedales que ocupan las } \\
\text { partes más bajas y deprimidas, próximas } \\
\text { a grandes cauces como el Sajama y } \\
\text { Tomarapi, y los bofedales situados } \\
\text { en partes altas, en la cabecera de las } \\
\text { quebradas y fondos de valle } \\
\text { Más naturales y menos transformados. }\end{array}$ \\
\hline $\begin{array}{l}\text { TIPOS DE BOFEDAL: } \\
\text { - Bofedal de aguas no } \\
\text { mineralizadas }\end{array}$ & - Suelos anegados. & $\begin{array}{l}\text { Dominio de cojines } \\
\text { compactos cuya } \\
\text { asociación es } \\
\text { Calamagrostio- } \\
\text { Distichietum. }\end{array}$ & Distichia muscoides & \\
\hline $\begin{array}{l}\text { - Bofedal } \\
\text { estacionalmente } \\
\text { inundado }\end{array}$ & $\begin{array}{l}\text { - Franjas periféricas } \\
\text { de las depresiones } \\
\text { y vegas que de } \\
\text { forma estacional } \\
\text { permanecen } \\
\text { anegadas }\end{array}$ & $\begin{array}{l}\text { - Morfología plana } \\
\text { o ligeramente } \\
\text { abombada. }\end{array}$ & $\begin{array}{l}\text { Scirpetum } \\
\text { deserticotae }\end{array}$ & \\
\hline $\begin{array}{l}\text { - Bofedal de aguas } \\
\text { mineralizadas }\end{array}$ & $\begin{array}{l}\text { - En áreas } \\
\text { permanentemente } \\
\text { anegadas, en } \\
\text { contacto con la } \\
\text { formación anterior. }\end{array}$ & $\begin{array}{l}\text { - Cojines } \\
\text { compactos aislados } \\
\text { y separados por } \\
\text { microcaudales }\end{array}$ & $\begin{array}{l}\text { Puccinellio frigidae } \\
\text { Oxychloetum } \\
\text { andinae }\end{array}$ & \\
\hline - Vegetación acuática & $\begin{array}{l}\text { - Márgenes de } \\
\text { lagunas y charcas } \\
\text { que se inundan } \\
\text { unos pocos } \\
\text { centímetros con } \\
\text { aguas estancadas } \\
\text { o ligeramente } \\
\text { fluyentes por } \\
\text { fusión glaciar o por } \\
\text { percolación freática. } \\
\text { - Es frecuente en } \\
\text { zonas limitrofes con } \\
\text { bofedales en aguas } \\
\text { no mineralizadas de } \\
\text { flujo muy lento. }\end{array}$ & $\begin{array}{l}\text { - Vegetación } \\
\text { palustre y } \\
\text { colonizadora desde } \\
\text { los bordes y orillas } \\
\text { hasta el centro } \\
\text { de las lagunas y } \\
\text { láminas de agua, } \\
\text { siendo refugio de un } \\
\text { elevado número de } \\
\text { aves. }\end{array}$ & $\begin{array}{l}\text { (Myriophyllum } \\
\text { quitensis } \\
\text { Potamogeton } \\
\text { fifliformis, } \\
\text { Lilaeopsis } \\
\text { macloviana } \\
\text { Ranunculus } \\
\text { uniflorus } \\
\text { Lachemilla } \\
\text { diplophyla }\end{array}$ & - Bien conservado \\
\hline
\end{tabular}




\begin{tabular}{|c|c|c|c|c|}
\hline PISO BIOCLIMÁTICO & \multicolumn{4}{|c|}{ CARACTERÍSTICAS } \\
\hline $\begin{array}{c}\text { PISO } \\
\text { CRIOROTROPICAL }\end{array}$ & \multicolumn{4}{|c|}{$\begin{array}{c}\text { Perteneciente a la Provincia o región biogeográfica Altiplánica. } \\
\text { Ocupa la zona altoandina superior y subnival de cerros y serranías volcánicas } \\
\text { por encima de los } 4.500 \mathrm{~m} \text {. }\end{array}$} \\
\hline Pajonal & $\begin{array}{l}\text { - Sobre suelos poco } \\
\text { geliturbados. } \\
\text { - Por encima de } \\
\text { los } 4.600 \mathrm{~m} \text { hasta } \\
5.200 \mathrm{~m} \text {. }\end{array}$ & $\begin{array}{l}\text { - Pajonal } \\
\text { amacollado abierto } \\
\text { o semiabierto. }\end{array}$ & $\begin{array}{l}\text { Festuca spp. } \\
\text { Azorella compacta }\end{array}$ & - Bien conservado \\
\hline Vegetación altoandina & $\begin{array}{l}\text { - Sobre suelos } \\
\text { geliturbados. } \\
\text { - Por encima de } \\
\text { los } 4.600 \mathrm{~m} \text { hasta } \\
5.200 \mathrm{~m} \text {. }\end{array}$ & $\begin{array}{l}\text { - Morfología } \\
\text { abierta constituida } \\
\text { por caméfitos y } \\
\text { hemicriptófitos } \\
\text { adaptados a los } \\
\text { suelos geliturbados. }\end{array}$ & & - Bien conservado \\
\hline
\end{tabular}

\ Figura 11. Cuadro que resume la vegetación de la puna de Sajama. Elaboración propia a partir de Navarro y Maldonado (2002) y datos del autor.

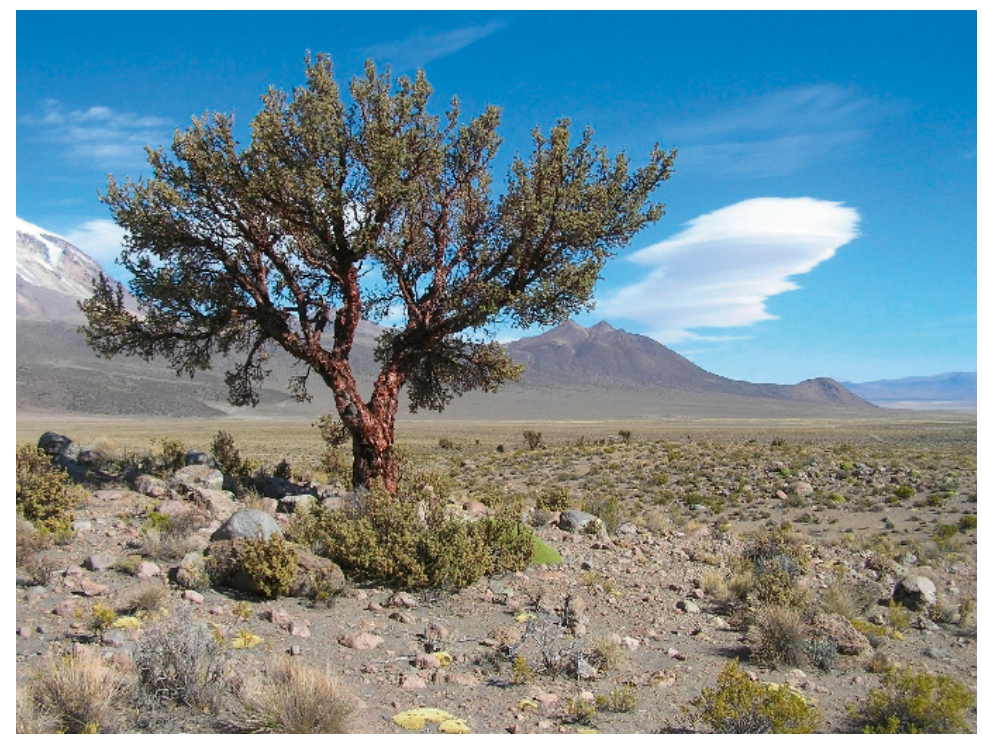

4 Figura 12. Queñua (Polylepis tarapacana). Foto del autor.

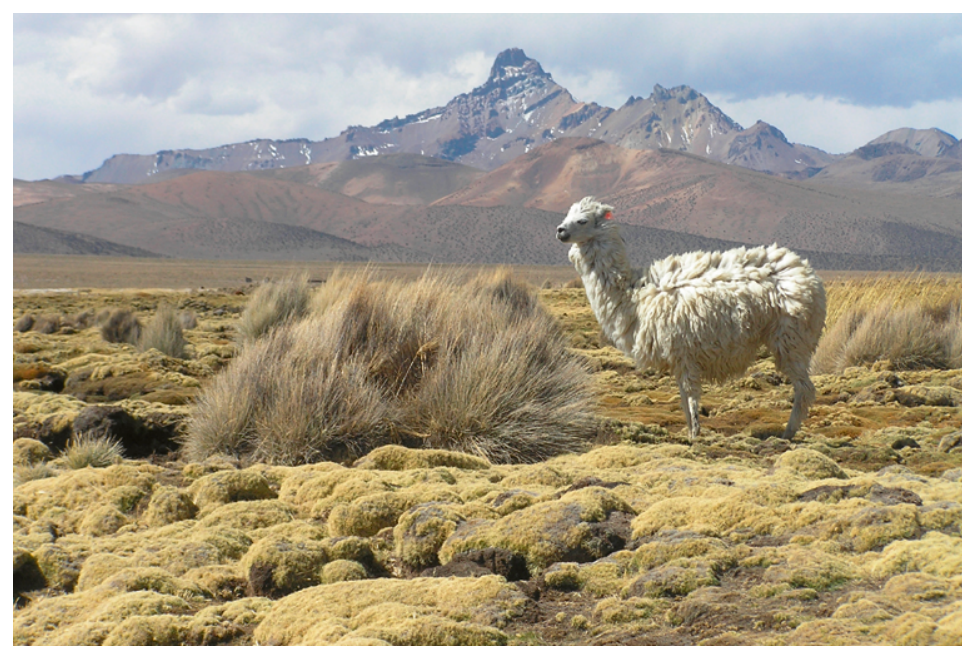

4 Figura 13. La principal fuente de alimento de las alpacas son los pastizales húmedos o "bofedales". Pampas del río Tomarapi. Foto del autor. 


\section{BIBLIOGRAFÍA}

Aguilera, M. José, Borderías, M. Pilar, González Yanci, P., Santos Preciado, J.M. (2010). Geografía general I. Geografía física. UNED Editorial.

Albó, X., Libermann, K., Godinez, A., Pifarré, F. (1990). Para comprender las culturas rurales de Bolivia. Ministerio de Educación y Cultura, CIPCA, UNICEF, La Paz, Bolivia, 298pp.

FJeLDSA, J./KESSLER, M. (2004). Conservación de la diversidad de los bosques de Polylepis de las tierras altas de Bolivia. Una contribución al manejo sustentable de los Andes. Editorial FAN Bolivia. Santa Cruz de la Sierra.

Garcia, E.; S.G. Beck (2006). "Praderas andinas y punas" en M. Morales et al. (Eds.). Botánica económica de los Andes centrales. La Paz, Universidad Mayor de San Andres, pp. 51-76.

IBISCH, Pierre L./MÉRIDA Gonzalo (2003). Biodiversidad: la riqueza de Bolivia, estado de conocimiento y conservación. FAN BOLIVIA EDITORIAL.

Mata Olmo, R., P. Aranguren, J., Bonilla Perdomo (2000). "La encrucijada de la protección de la naturaleza en Paraguay" en B. Valle Buenestado (Ed.): Geografía y espacios protegidos. Murcia, Asociación de Geógrafos Españoles: Federación de Espacios Naturales Protegidos de Andalucia, pp. 213-232.
MONTES DE OCA, I. (1997). Geografía y recursos naturales de Bolivia. La Paz, Edición del autor, 614 pp.

Murra, J.V. (2002). El mundo andino. Población, medio ambiente y economía. Lima, Instituto de Estudios Peruanos, Pontificia Univ. Católica del Perú, 511 pp., Selección de textos destacados e inéditos.

Navarro, Gonzalo/Maldonado Mabel (2002). Geografía Ecológica de Bolivia, vegetación y ambientes acuáticos. FUNDACIÓN SIMÓN PATIÑO.

NIELSEN, A. (2004). Aproximación a la arqueología de la frontera tripartita, Bolivia-Chile-Argentina. Chungará, revista de Antropología Chilena. Edición Especial. pp. 861-878.

SÁnchez, IVÁN A. (2011). De Amazonía a Patagonia. Ecología de las regiones naturales de América del Sur. Lynx ediciones. Barcelona.

SerRano CañadAs, E. (1998). Geomorfología estructural, una introducción. Santander.

SWedish Geological AB., Suecia (1995). Thematic maps of mineral resoruces of Bolivia. Servicio Geológico de Bolivia.

Pedraza Gilsanz, J. (1996). Geomorfología, principios, métodos y aplicaciones. Rueda. Madrid.

WhiтTOW, J. (1988). Diccionario de Geografía Física. Alianza editorial.

YAGER, H. Resnikowski \& S. Halloy (2008). Grazing and climatic variability in Sajama National Park, Bolivia. Pirineos, 163: 97 a 109, Jaca. 
